\title{
Diagnosis of Respiratory Bronchiolitis associated interstitial lung disease
}

\author{
C. Robalo Cordeiro1, S. Freitas'1, B. Rodrigues'1, A. Catarino1, \\ M.J. Matos ${ }^{1}$, I. Ferreira 1 , L. Carvalho 2
}

ABSTRACT: Diagnosis of Respiratory Bronchiolitis associated interstitial lung disease. C. Robalo Cordeiro, S. Freitas, B. Rodrigues, A. Catarino, M.J. Matos, I. Ferreira, L. Carvalho.

Background. Respiratory Bronchiolitis (RB), described by Niewoehner et al in 1974, is a common finding in heavy smokers and is characterised by the presence of pigmented macrophages within respiratory bronchioles and adjacent alveoli.

In the 1980s, Myers et al described RB associated with interstitial lung disease (RBILD), which is a rare entity expressed as an amplified respiratory bronchiolitis in response to cigarette smoke.

Methods. The authors studied a group of 8 patients with biopsy-proven RBILD diagnosed within the last five years, and assessed epidemiological data, clinical and imaging features, lung function tests, bronchoalveolar lavage findings, therapeutic approaches and clinical evolution.
Results and Conclusions. The most difficult differential diagnosis is between RBILD and Desquamative Interstitial Pneumonia (DIP), which seems to suggest that these disorders are either end of the same spectrum, although the authors claim that there are some clinical, morphological and prognostic distinctions. The diagnosis of RBILD requires an appropriate clinical setting (including smoking habits), characteristic image findings (like ground glass shadowing and centrilobular nodules), and Bronchoalveolar Lavage (BAL) data to exclude other diagnosis.

Pathological confirmation may also be important, not only to exclude more adverse interstitial lung disease, such as idiopathic pulmonary fibrosis, but also, as in the eight cases presented, to illustrate some specific features such as the prevalence of lymphocytosis in BAL.

Monaldi Arch Chest Dis 2006; 65: 2, 96-101.

Keywords: Respiratory Bronchiolitis; Interstitial Lung Disease; Smoking; Bronchoalveolar Lavage; Desquamative Interstitial Pneumonia.

1 Department of Pneumology and Allergology, University Hospital of Coimbra.

2 Pathology Institute, University Hospital of Coimbra, Portugal.

Correspondence: Department of Pneumology and Allergology; University Hospital of Coimbra; 3000 Coimbra, Portugal; e-mail: crobalo@mail.telepac.pt

\section{Introduction}

Respiratory Bronchiolitis (RB), was described by Niewoehner et al in 1974 [1] as an incidental finding in an autopsy study carried out on smokers, primarily young males, who died suddenly from non-pulmonary disease. This finding is common in heavy smokers and is also known as "smoker's bronchiolitis" [2].

$\mathrm{RB}$ is characterised by the presence of pigmented macrophages within respiratory bronchioles and adjacent alveoli [2], displayed as peribronchiolar inflammation and not usually associated with extensive parenchymal disease.

In the 1980s, Myers et al described RB as the only histopathological finding in a group of six patients within a clinico-radiological context of interstitial lung disease [3].

$\mathrm{RB}$ associated with interstitial lung disease (RBILD) is a rare disorder in which hypertrophied respiratory bronchiolitis occurs in response to cigarette smoke.
The differential diagnosis between these two disorders is based upon the degree of severity, in which RBILD is a clinical relevant disease, indicated by clinical, radiological and physiological evidence of chronic lung interstitial involvement, probably representing a subgroup of smokers at the more severe end of the spectrum of BR [4].

Tobacco smoking is the main risk factor in the development of Chronic Obstructive Pulmonary Disease and the major cause of Lung Cancer and there is evidence supporting its relationship with interstitial lung damage.

In this context, cigarette smoking has been identified as a causative agent in some interstitial lung disorders, like Desquamative Interstitial Pneumonia (DIP), Langerhans' Cell Histiocytosis and RBILD, the so called "smoking related interstitial lung diseases" [5].

In addition, smoking appears to be a risk factor in the pathogenesis of Idiopathic Pulmonary Fibrosis, that is Usual Interstitial Pneumonia (UIP) and Non-specific Interstitial Pneumonia (NSIP), 
although there is some controversy as to this association [6].

The evolution of the classification of Idiopathic Interstitial Pneumonias, from Liebow [7] to Katzenstein [8], adds to the initially described DIP, the new pattern of RBILD, and even suggests that RBILD should replace DIP as a unifying term.

Nevertheless, these interstitial disorders, although possibly having smoking in common, must be differentiated from each other from a histological point of view.

RBILD is characterised histologically by the presence of pigmented macrophages and interstitial inflammatory response focusing on respiratory bronchioles and adjacent alveol. These alterations are more extensive and diffuse in DIP and are not limited to the peribronchiolar parenchyma.

Besides this difference in relation to the extent of the inflammatory process, with a more undefined profile in RBILD, there are many other distinctions that can be made between RBILD and DIP, which will be emphasised by the authors in this discussion.

\section{Methods}

The authors studied a group of 8 patients with biopsy-proven Respiratory Bronchiolitis and Interstitial Lung Disease (RBILD) diagnosed within the last five years and assessed epidemiological data, clinical and imaging features, lung function tests, endoscopic findings including bronchoalveolar lavage, therapeutic approaches and clinical evolution.

\section{Results}

There were seven men and one woman with ages ranging between 28 and 63 years. All patients were current smokers, the amount smoked ranging from 13 to 60 pack years. Two had additional occupational exposures, one in construction work and another as a fireman. There were no signifi- cant comorbilities. The clinical features are shown in table 1 .

The slight male predominance found in RBILD $[3,5]$ was reinforced in this study by the ratio $7 / 1$ (male/female), with the mean age of about 43 years which is in accordance with the literature.

Virtually all patients with RBILD are current or former heavy smokers, but there is evidence of the occurrence of this disease in non-smokers with occupational airborne exposures, as in the case of a 35 year-old female non-smoker patient exposed to solder flux fumes studied by Moon et al [9]. Also Canessa et al described recently [10] a case report of a 52 year-old male smoker who was a mechanic by profession and exposed to a large amount of toxic substances, including acid and exhaust fumes, asbestos fibres, oil and oily liquids.

In our study two patients were smokers and also had occupational exposures, one in construction work, and the other was a fireman, curiously the youngest patient (28 year-old) was admitted with a pneumothorax.

Two patients were admitted with a pneumothorax, confirming the high prevalence of tobaccorelated disease in patients with this occurrence, as Cottin et al described [11], showing that RBILD was present in almost $90 \%$ out of a set of 79 smokers with spontaneous pneumothorax requiring surgical pleurodesis.

All patients were symptomatic on admission. Productive cough was the most common symptom, present in seven patients, followed by shortness of breath worse on exertion, in six patients, and chest discomfort. On examination, three patients had basal crackles while five had diminished or abolished breath sounds. None had digital clubbing, which only occasionally has been described in RBILD [12].

The imaging features are shown in table 2. A chest radiography revealed pneumothorax in two patients, one of which was a tension pneumothorax. Two other patients showed alveolar-interstitial

Table 1. - Clinical Features

\begin{tabular}{|c|c|c|c|c|c|c|c|c|}
\hline \multicolumn{9}{|c|}{ Case no. } \\
\hline & 1 & 2 & 3 & 4 & 5 & 6 & 7 & 8 \\
\hline Age (years) & 28 & 35 & 38 & 57 & 40 & 64 & 44 & 40 \\
\hline Sex & M & M & M & M & M & M & $\mathrm{F}$ & M \\
\hline Smoking (pack years) & 13 & 24 & 25 & 35 & 40 & 60 & 30 & 35 \\
\hline Occupational exposure & Fireman & \multicolumn{7}{|c|}{ Construction worker } \\
\hline \multicolumn{9}{|l|}{ Clinical findings } \\
\hline Cough & Yes & Yes & Yes & Yes & Yes & Yes & Yes & No \\
\hline Sputum & No & Yes & Yes & Yes & Yes & Yes & Yes & No \\
\hline SOB & No & Yes & Yes & Yes & Yes & Yes & Yes & No \\
\hline Chest discomfort & Yes & Yes & No & No & No & Yes & No & Yes \\
\hline Haemoptysis & No & No & No & No & No & Yes & No & No \\
\hline Fever/weight loss & No & No & No & No & Yes & No & No & No \\
\hline Basal crackles & No & Yes & No & Yes & Yes & No & No & No \\
\hline Diminished lung sounds & Yes & Yes & Yes & Yes & No & No & No & Yes \\
\hline Recurrent infections & No & No & Yes & Yes & No & Yes & No & No \\
\hline
\end{tabular}




\begin{tabular}{|c|c|c|c|c|c|c|c|c|}
\hline & Case no. & & & & & & & \\
\hline & 1 & 2 & 3 & 4 & 5 & 6 & 7 & 8 \\
\hline Chest Radiography & Pnthorax & $\begin{array}{c}\text { Alveolar } \\
\text { interstitial }\end{array}$ & $\begin{array}{l}\text { Reticular } \\
\text { nodular }\end{array}$ & $\begin{array}{c}\text { Alveolar } \\
\text { interstitial }\end{array}$ & $\begin{array}{l}\text { Reticular } \\
\text { nodular }\end{array}$ & $\begin{array}{l}\text { Reticular } \\
\text { nodular }\end{array}$ & $\begin{array}{l}\text { Reticular } \\
\text { nodular }\end{array}$ & Pnthorax \\
\hline CT Scan & No & Yes & Yes & Yes & Yes & Yes & Yes & $\begin{array}{c}\text { Yes } \\
\text { (post drainage) }\end{array}$ \\
\hline Reticulonodular & & Yes & Yes & Yes & Yes & Yes & No & No \\
\hline Ground Glass & & Yes & Yes & No & Yes & Yes & Yes & No \\
\hline Emphysema & & Yes & No & No & No & Yes & No & Yes \\
\hline Bronchial wall thickening & & No & No & No & Yes & No & Yes & No \\
\hline
\end{tabular}

Pnthorax $=$ Pneumothorax

pattern, and four had reticular or reticulonodular shadowing. A chest CT scan was performed on seven patients, although in one case only after chest tube drainage. Five of the seven patients showed reticulonodular pattern, correlated to patchy ground glass areas in four patients and emphysematous alteration in two. One patient had ground glass shadowing and another showed only emphysematous alteration.

Small-airway disorders are not easy to evaluate using conventional radiography, but high-resolution computed tomography (HRCT) has led to a considerable improvement in the accuracy of diagnosing these entities, often showing characteristic findings.

In this context, we can observe in figure 1, non-specific reticulonodular attenuation presented in the chest radiograph of patient 2 .

However, the most characteristic finding of HRCT in RBILD consists of poorly defined centrilobular nodules and bilateral ground-glass opacities [13]. These alterations are visible in the HRCT section from patient 4 shown in figure 2, as are other characteristic findings which frequently occur in heavy smokers, such as emphysematous changes.

It seems that by correlating these imaging findings with the morphological disturbances, the ex-

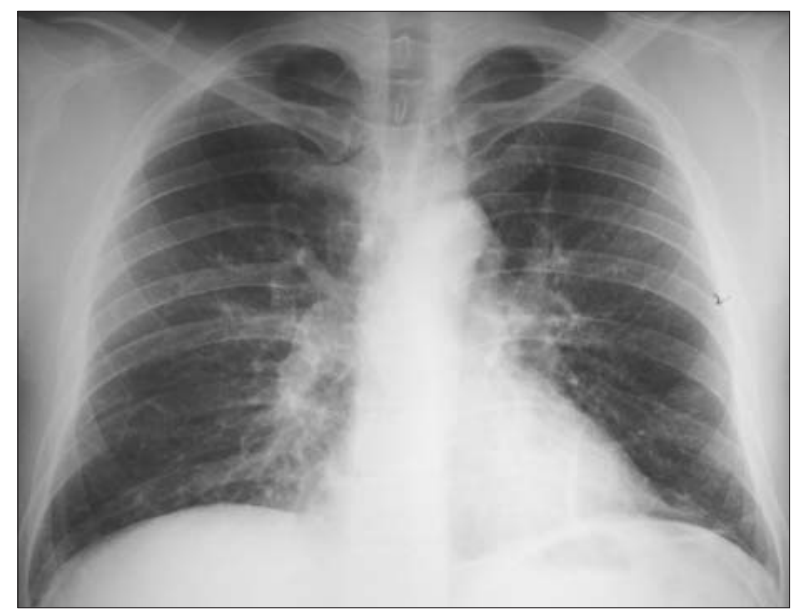

Fig. 1. - Chest-X-ray. Diffuse reticulonodular shadowing (patient 2). tent of centrilobular nodules could be related to the degree of inflammation and extent of macrophages in respiratory bronchioles, whereas the groundglass shadowing could be attributed to macrophage accumulation in alveolar ducts and alveoli $[13,14]$. In other words, ground-glass attenuation could reflect "smoker's alveolitis" whereas micronodules would correspond to respiratory bronchiolitis $[15,16]$ (as can be observed in the morphologic appearance from a surgical biopsy performed on patient 3 - figure 3 ).

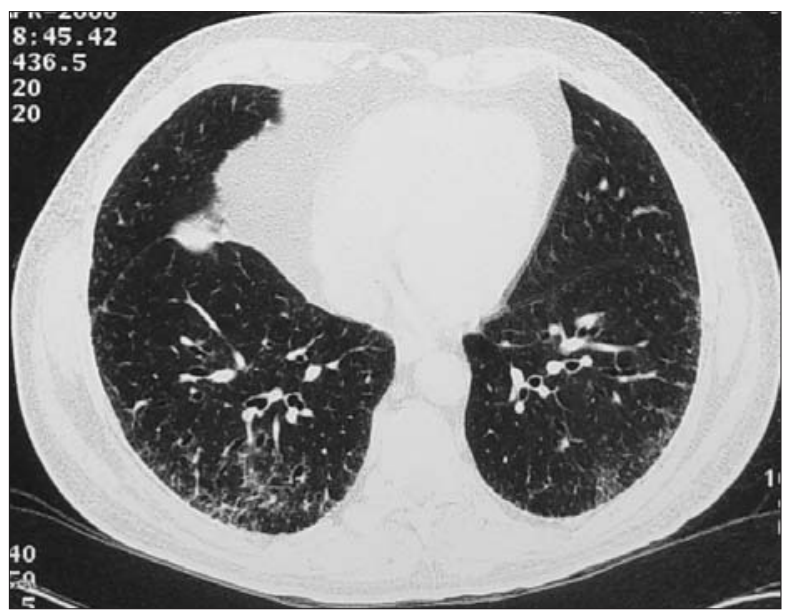

Fig. 2. - HRCT of the thorax. Subpleural micronodular pattern and ground glass opacities (patient 4).

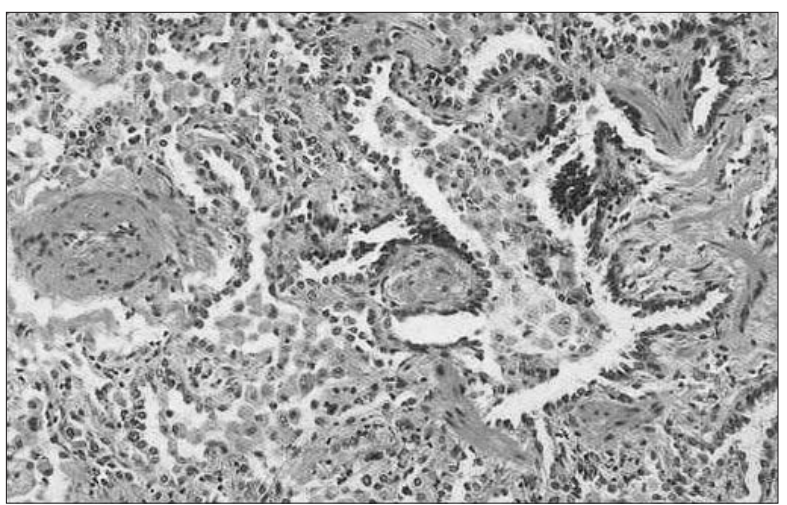

Fig. 3. - Lung surgical biopsy - Microscopic findings. Interalveolar septa with inflammatory cells and collagen (ILD), and respiratory bronchiolitis with macrophagic shedding (patient 3). 
Lung function tests, shown in table 3 , were performed on seven patients. Three patients had normal lung function tests. Two showed a mild restrictive ventilatory defect while the other two revealed slight airflow obstruction. In four patients, there was a gas transfer deficit, defined as mild to moderate (between 60 and 75\%).

Six patients were submitted to fiberoptic bronchoscopy, with Bronchoalveolar Lavage (BAL) performed on five. There were no significant macroscopic changes in three patients or endoscopic signs of chronic bronchitis in the other three. BAL revealed a high cell count trend in almost all patients, and moderate lymphocytosis in four of them (table 4). The CD4/CD8 ratio was lower than one in all five patients.

Treatment options and clinical evolution are shown in table 5 .

The treatment advocated was ceasing to smoke and measures to address symptoms. Associated infections were treated with antibiotics. Systemic corticosteroids or other immunosuppression were not administered. One patient responded well to inhaled bronchodilators.

Clinical evolution was determined after reevaluation (mean follow-up time of 22 months) of lung function tests and imagiological features. The classification (improved; stable; deteriorated) may include any of these parameters. For functional evaluation, we used criteria described in previous studies [9]: improved $=$ an over $15 \%$ increase in TLCO, stable $=$ absence or minor changes (up to $15 \%)$, deteriorated $=$ an over $15 \%$ decrease $($ TLCO was chosen as it is the functional parameter most often abnormal in our patients). As to imaging, we used criteria based on sequential evaluation of CT scans, assessed by a pulmonary radiologist.

In this study, seven of the eight patients remained stable or showed improvement, one patient subsequently died of an unassociated malignant disease and the one patient that was unable to give up smoking showed both functional and imagiological deterioration.

Table 3. - Lung Function Tests

\begin{tabular}{|c|c|c|c|c|c|c|c|c|}
\hline \multicolumn{9}{|c|}{ Case no. } \\
\hline & 1 & 2 & 3 & 4 & 5 & 6 & 7 & 8 \\
\hline $\mathrm{FEV}_{1}$ & & 73.5 & 105 & 107 & 69.9 & 77.1 & 111.9 & 87.8 \\
\hline $\mathrm{FVC}$ & & 73.7 & 107 & 100 & 75.7 & 75.2 & 119.1 & 116.5 \\
\hline $\mathrm{FEV}_{1} / \mathrm{FVC}$ & & 82.8 & 84.6 & 85 & 77.3 & 82.1 & 80.9 & 75.4 \\
\hline TLC & & 77.9 & 94.2 & 92.9 & 89.4 & 71 & 97.7 & 83.3 \\
\hline $\mathrm{TL}_{\mathrm{CO}}$ & & 63.2 & 83.3 & 82.4 & 64.4 & 68.3 & 80.6 & 71.2 \\
\hline
\end{tabular}

All values are percentage predicted.

Table 4. - BAL findings

\begin{tabular}{lcccccccc}
\hline \multicolumn{1}{c}{ Case no. } & \multicolumn{1}{c}{} & & & & \\
\hline & $\mathbf{1}$ & $\mathbf{2}$ & $\mathbf{3}$ & $\mathbf{4}$ & $\mathbf{5}$ & $\mathbf{6}$ & $\mathbf{7}$ & $\mathbf{8}$ \\
\hline Cels/ml x 103 & & 230 & 120 & 390 & 290 & & 270 \\
Macrophages & & $77 \%$ & $72 \%$ & $75 \%$ & $71 \%$ & $82 \%$ \\
lymphocytes & & $20 \%$ & $28 \%$ & $23 \%$ & $25 \%$ & $15 \%$ \\
neutrophils & & $3 \%$ & $0 \%$ & $2 \%$ & $4 \%$ & $2 \%$ & \\
CD4/CD8 & & 0.36 & 0.30 & 0.61 & 0.22 & .47 \\
\hline
\end{tabular}

Table 5. - Treatment options and clinical evolution

\begin{tabular}{|c|c|c|c|c|c|c|c|c|}
\hline \multicolumn{9}{|c|}{ Case no. } \\
\hline & 1 & 2 & 3 & 4 & 5 & 6 & 7 & 8 \\
\hline \multicolumn{9}{|l|}{ Treatment } \\
\hline Quit smoking & Yes & No & Yes & Yes & Yes & Yes & Yes & Yes \\
\hline Antibiotics & & Yes & & & Yes & Yes & & \\
\hline Bronchodilator & & & & & Yes & & & \\
\hline Evolution & I & $\mathrm{D}$ & I & S & S & $\mathrm{I}^{*}$ & S & I \\
\hline
\end{tabular}

I=Improved; S=Stable; D=Deteriorated; *=died of unassociated disease. 


\section{Discussion}

In relation to pulmonary function tests, although the literature refers to the possibility of having a mixed obstructive-restrictive pattern (in our study ventilatory defects were present separately in four patients; two obstructives and two restritives), with a slightly reduced diffusing capacity (seen also in four patients), it is also possible to have normal tests (found in three patients), demonstrating the low specificity of this approach $[5,17]$.

The most prevalent ventilatory pattern is probably a mixed one, with a predominantly restrictive defect and a moderate reduction in diffusing capacity [4]. However, Myers et al [3] described, in a specific case study of eight patients with RB that four had restrictive lung function tests and three also showed obstruction. TLCO was moderately decreased in the other four cases. Also, Ryu et al [18] showed that in twelve cases with RBILD, there were five restrictive and three obstructive profiles. Of these the TLCO was diminished in some cases; there was one patient with normal lung function test and one who only showed a defect in diffusing capacity.

The major utility of BAL lies in the distinction between RBILD and other diffuse lung diseases, with the findings of increased macrophage numbers (with their characteristic brown pigmentation) and lower percentages of other cellular components allowing differentiation between RBILD and both UIP and NSIP, including its fibrotic pattern [19]. The presence of BAL neutrophilia or eosinophilia appears to be very rare, and the augmented lymphocitic number is also unusual, which we have found on occasion in our patients. This finding requires other differential diagnosis, such as Hypersensitivity Pneumonitis (HP).

There are several arguments to exclude this disorder in the eight cases presented:

1) the lack of a consistent or known antigenic risk exposure in all the patients;

2) the mean percentage of lymphocytosis in BAL, approximately $22 \%$, which is much lower than that expected in HP, which is usually higher than $40 \%$;

3) the absence of granulomatous lesions in the morphologic approach;

4) smoking habits in all the samples, which is a typical condition in RBILD and is not so prevalent in HP.

The mean follow-up time of 22 months in our study (under a clinical, functional and imagiological control) was enough to show a stable or improved status in all patients who stopped smoking, confirming smoking cessation as the only efficacious therapy in this disease.

However, the timing in which respiratory bronchiolitis, assessed by BAL macrophagic population, clears up after ceasing smoking, appears to be highly variable as described by Agius et al [20], who reported a normalisation of macrophage percentages within 3 years, and by Fraig et al [21], who showed absence of respiratory bronchiolitis in less than 1 year in some ex-smokers and persis- tence of abnormalities more than 10 years after stopping smoking in another group of patients.

In summary, the diagnosis of RBILD requires the appropriate clinical setting, which includes smoking habits, existence of symptoms, especially cough and dyspnea and the presence of crackles on chest examination, the imaging findings, mainly patchy ground glass opacities and centrilobular nodules on HRCT scanning, and also BAL data to exclude other diagnosis.

These eight cases could reinforce the argument that, under specific circumstances, like the unusual BAL cellularity observed, a pathologic confirmation may be needed, in addition to the obligatory exclusion of more adverse interstitial lung disease, such as idiopathic pulmonary fibrosis.

However, the most difficult differential diagnosis may be with DIP, as suggested by some authors, who have put forward the view that DIP and RBILD could be at either end of the same spectrum [17].

Besides the histological distinction raised in the introduction and the more intense ground-glass attenuation pattern in DIP discussed, there are some specific features like the more frequent occurrence of DIP in non-smokers than RBILD and the fact that only patients with DIP died [18], which could support the argument that these interstitial disorders are two separate entities. There is no evidence to show that RBILD could progress to DIP [4], although both are included in the so called "smoking related interstitial lung diseases".

Acknowledgment: The authors are indebted to Jessica Cemlyn-Jones, resident in the Department of Pneumology and Allergology, for reviewing the text.

\section{References}

1. Niewoehner DE, Kleinerman J, Rice DB. Pathologic changes in the peripheral airways of young cigarette smokers. N Engl J Med 1974; 291: 755-758.

2. Colby TV. Bronchiolitis: pathologic considerations. Am J Clin Pathol 1998; 109: 101-109.

3. Myers JL, Veal CFJr, Shin MS, Katzenstein ALA.Respiratory bronchiolitis causing interstitial lung disease. A clinicopathologic study of six cases. Am Rev Respir Dis 1987; 135: 880-884.

4. Wells AW, Nicholson AG, Hansel DM, duBois RM. Respiratory Bronchiolitis-Associated Lung Disease. Semin Resp Crit Care Med 2003; 24: 585-594.

5. Ryu JH, Colby TV, Hartman TE, Vassalo R. Smokingrelated interstitial lung diseases: a concise review. Eur Respir J 2001; 17: 122-132.

6. Hansel DM, Nicholson AG. Smoking-Related Diffuse Parenchymal Lung Disease: HRCT-Pathologic Correlation. Semin Resp Crit Care Med 2003; 24: 377-391.

7. Liebow AA. Definition and classification of interstitial pneumonias in human pathology. Progr Respir Res 1975; 8: 1-31

8. Katzenstein ALA, Myers JL. Idiopathic Pulmonary Fibrosis. Am J Respir Crit Care Med 1998; 157: 13011315.

9. Moon J, DuBois RM, Colby TV, Hansel DM, Nicholson AG. Clinical significance of respiratory bronchiolitis on open lung biopsy and its relationship to smoking related interstitial lung disease. Thorax 1999; 54: 1009-1014. 
10. Canessa PA, Pratticò L, Bancalari L, Fedeli F, Bacigalupo B, SilvanoS. Respiratory bronchiolitis associated with interstitial lung disease. Monaldi Arch Chest Dis 2004; 61: 3, 174-176.

11. Cottin V, Streichenberger N, Gamondès JP, Thévenet F, Loire R, Cordier JF. Respiratory bronchiolitis in smokers with spontaneous pneumothorax. Eur Respir J 1998; 12: 702-704.

12. Sadikot RT, Johnson J, Loyd JE, Christman JW. Respiratory bronchiolitis associated with severe dyspnea, exertional hypoxemia, and clubbing. Chest 2000; 117: 282-285.

13. Franquet T, Müller NL. Disorders of the Small Airways; High-Resolution Computed Tomographic Features. Semin Resp Crit Care Med 2003; 24: 437-443.

14. Park JS, Brown KK, Tuder RM, Hale VA, King Jr TE, Lynch DA. Respiratory bronchiolitis-associated lung disease: radiological features with clinical and pathologic correlation. J Comput Assist Tomogr 2002; 26: 13-20.

15. Heyneman LE, Ward S, Lynch DA, Remy-Jardin M, Johkoh T, Müller NL. Respiratory bronchiolitis, respiratory bronchiolitis-associated interstitial lung disease, and desquamative interstitial pneumonia: different entities or part of the spectrum of the same disease process? Am J Roentgenol 1999; 173: 1617-1622.
16. Remy-Jardin M, Remy J, Gosselin B, Becette V, Edme JL. Lung parenchymal changes secondary to cigarette smoking: pathologic-CT correlations. Radiology 1993; 186: 643-651.

17. Elkin SL, Nicholson DM, duBois RM. Desquamative Interstitial Pneumonia and Respiratory BronchiolitisAssociated Interstitial Lung Disease. Semin Resp Crit Care Med 2001; 22: 387-397.

18. Ryu JH, Myers JL, Capizzi SA, Douglas WW, Vassalo R, Decker PA. Desquamative Interstitial Pneumonia and Respiratory Bronchiolitis-Associated Lung Disease. Chest 2005; 127: 178-184.

19. Veeraraghavan S, Latsi PI, Wells AU, et al. BAL findings in idiopathic non-specific interstitial pneumonia and usual interstitial pneumonia. Eur Respir J 2003; 22: 239-244.

20. Agius RM, Rutman A, Knight RK, Cole PJ. Human pulmonary alveolar macrophages with smokers' inclusions: their relation to the cessation of cigarette smoking. Br J Exp Pathol 1986; 67: 407-413.

21. Fraig M, Shreesha U, Savici D, Katzenstein ALA. Respiratory bronchiolitis: a clinicopathologic study in current smokers, ex-smokers and never-smokers. Am $J$ Surg Pathol 2002; 26: 647-653.

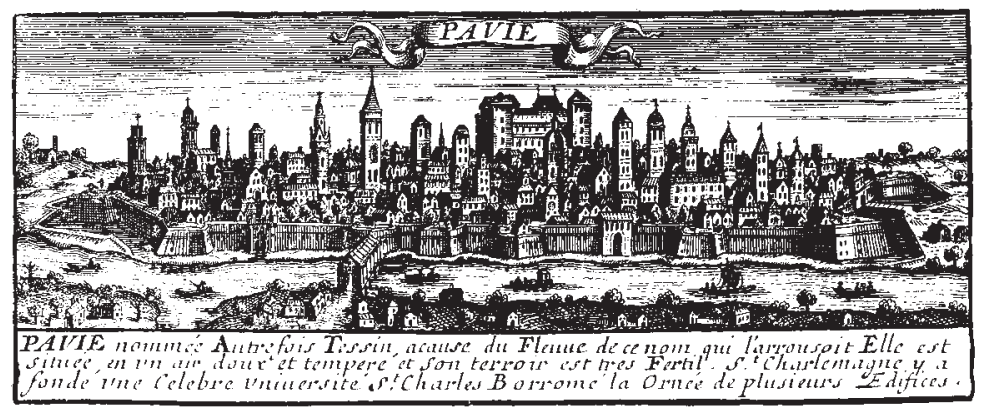

